\title{
Design para o cinema: metodologia de design de produto no projeto de objetos cinematográficos
}

\author{
Design for film production: product design methodology for the development of \\ cinematographic objects
}

\author{
ANDRADE, Ana Paula Romero; Graduanda; Universidade Federal de Juiz de Fora \\ anapromeroandrade@gmail.com
}

XAVIER, Silvia Resende; Mestre; Universidade Federal de Juiz de Fora

silviarx@gmail.com

\begin{abstract}
Resumo
Este trabalho tem como objetivo principal o estudo da aplicação da metodologia de design de produto na concepção e desenvolvimento de um objeto para uma produção cinematográfica. A metodologia desta pesquisa compreende a revisão de literatura, a realização de um projetomodelo, a análise dos dados das pesquisas teórica e empírica, e a síntese de resultados. Nesse estudo, observa-se que a aplicação da metodologia de design no desenvolvimento do objeto cinematográfico permite uma exploração e definição cuidadosa da demanda, resultando em um conhecimento claro do problema e em consequência o planejamento sistemático de uma solução pertinente. Evidencia-se a importância da integração entre os campos do cinema e do design para o processo de ampliação da discussão acerca das interseções e dos espaços para atuação do designer.
\end{abstract}

Palavras Chave: objeto cinematográfico; design; metodologia.

\begin{abstract}
The main objective of this paper is to study the application of product design methodology in the creation and development of an object for a cinematographic production. The research methodology for this study includes literature review, the execution of an experimental project, the analysis of the theoretical and empirical research data, and the synthesis of results. In this study, it is stated that the application of design methodology in the development of a cinematographic object allows a careful exploration and definition of the demand, resulting in a clear understanding of the problem and in a systematic planning of a pertinent solution. The importance of integrating design and film production is evidenced, as it contributes to the discussion about the intersections of the design activity and the spaces where a designer can work.
\end{abstract}

Keywords: cinematographic object; design; methodology. 


\section{Introdução}

O cinema, como meio de expressão, se constrói como ferramenta de difusão de uma carga simbólica significativa. Sendo uma prática social tanto dos que o produzem quanto dos que o consomem, ele pode se configurar como um dos principais agentes no processo de representações sociais perpetuadas nos imaginários coletivos (GUTEMBERG, LIRA, 2016). Tuner (1997, p.13) afirma que, nas narrativas e significados presentes nos filmes, "podemos identificar evidências do modo como nossa cultura dá sentido a si própria".

A narrativa cinematográfica possui características próprias se comparada a outros meios como, por exemplo, a literatura, pois ela conta com elementos visuais, sonoros e textuais (GUTEMBERG e LIRA, 2016). A matéria-prima de um filme é a soma da imagem à narrativa verbal, que resulta em uma realidade complexa guiada por fatores técnicos e pelos desejos do diretor, produzindo, portanto, uma imagem fílmica com uma concepção visual múltipla sobre um mesmo argumento. Em suma, como coloca Machado (2009, p.38), "o filme é a soma poética de uma grande quantidade de elementos narrativos, sonoros e visuais, baseados no roteiro".

A ligação entre cinema e design é estreita, apesar de existir, até os dias de hoje, uma falta de claridade das interseções entre os dois campos (COELHO, 2006). Uma das aproximações possíveis na conexão entre design e cinema é a interpretação do cinema como um campo para a manifestação de experiências de designers, justificando assim a difusão crescente de termos como "design de produção", "design de som", "design narrativo", "design de cor", "design de figurino", entre tantos outros (FILHO, FILHO, DINIZ, 2015). A mudança do termo "direção de arte" para "design de produção", oriunda, em parte, dos avanços tecnológicos desse campo, evidencia a preponderância do design na formulação de soluções nos processos de realização dos filmes (BAPTISTA, 2008). Ao conceber as relações entre cinema e design na atualidade, Filho, Filho e Diniz (2015, p.247) apontam que é imperativo "analisar, descrever, modelar e propor inovações em áreas específicas como design de produção, design de som, design de cenários (físicos e digitais), design de figurino, entre outros". Umas dessas interseções entre design e cinema diz respeito à escolha ou à concepção de objetos que serão parte de um filme.

Considerando que o objeto possui um sentido preponderante na cultura, visto que as coisas que nos cercam dão forma à identidade de seus usuários, o objeto cinematográfico apresenta, em conjunto com o espaço, tempo, personagens e diálogos, uma função importante na condução narrativa do filme (COELHO, 2003). A produção desses objetos pressupõe um tratamento específico, dado que ele alcança o seu público final por meio de um filtro, a imagem cinematográfica. Consumidos por intermédio da tela cinematográfica, a função principal desses objetos é sua forma visual, e não a função prática que se espera no mundo real.

O objeto de cena, além de cumprir sua função visual e de exercer funções práticas no contexto do filme, também contribui para o arco narrativo, e é possível representar certas características e emoções através de tais objetos. Ao falar sobre o desenvolvimento da VoightKampff machine, projetada para o filme Blade Runner (Blade Runner, USA, Stcot Ridley, 1982, $117 \mathrm{~min})$, o designer Syd Mead comenta sobre as definições de características do objeto para que ele provoque determinadas emoções e reações do público, contribuindo assim para a narrativa do filme: 
de uma mesa, muito ameaçadora, como uma espécie de tarântula gigante. Como não é perigoso porque é grande, tinha que ser perigoso porque é ameaçador. Então, decidimos que deveria respirar. Minha razão para isso era que a máquina aspiraria amostras de ar na área próxima. Quando você está com medo ou apreensivo, nosso corpo emite um odor[...]. Você abre a máquina e ela opera sozinha assim que o sujeito entra na sala; o braço se move e ela se foca no olho do suspeito. Ela é meio viva de uma maneira por si só, e é muito, muito ameaçador. ${ }^{1}$ (XIRDAL, 2006) (Tradução da autora)

Entende-se que os objetos cinematográficos são elementos cruciais de uma produção cinematográfica e, nesse contexto, a concepção de tais objetos é uma atividade importante. Considerando suas características gerais, como a materialidade, a função prática, e a interação com as pessoas em cena, o objeto cinematográfico se assemelha a um objeto do dia a dia. Seu desenvolvimento pode, portanto, ser de responsabilidade de profissionais do design de produto, pautados pelas definições do designer de produção e do diretor. No entanto, o objeto cinematográfico tem algumas peculiaridades, como a sua função simbólica e sua conexão com a narrativa, que podem demandar adaptações no processo de desenvolvimento do objeto.

O objetivo principal deste artigo é estudar a aplicação e a adequação da metodologia de design de produto no desenvolvimento de objetos para uma produção cinematográfica. Este estudo tem como objetivos específicos: entender as relações entre produções cinematográficas e design; analisar a importância do objeto cinematográfico e sua participação na narrativa; e avaliar a adequação da metodologia de design de produto para o desenvolvimento de objetos cinematográficos. Para esse estudo, além da revisão teórica, apresenta-se a discussão da aplicação da metodologia de design na concepção de um objeto cinematográfico. Em um contexto frequentemente pautado por resultados empíricos registrados informalmente, uma abordagem estruturada e embasada de experiências práticas da interação entre design e cinema contribui para o conhecimento científico em ambas as áreas, com foco no estudo de métodos de projeto.

\section{Metodologia}

A metodologia para essa pesquisa é composta de quatro etapas. Primeiramente, a base teórica é construída a partir de pesquisa bibliográfica e tem por objetivo evidenciar as relações entre design, cinema e objetos. Essa etapa da pesquisa contempla o entendimento da atuação de designers na indústria cinematográfica; a compreensão da relevância do objeto cinematográfico e sua conexão com a narrativa; e a identificação de metodologias de design e seu potencial para o desenvolvimento de produtos cinematográficos.

$\mathrm{Na}$ etapa exploratória da pesquisa, é descrito o processo de desenvolvimento de um objeto cinematográfico a partir da utilização de metodologia de design de produto. Esse projeto é usado como um projeto-modelo e a descrição de seu processo de desenvolvimento e de seus resultados fornece dados para avaliar a adequação da metodologia de design para a concepção deste tipo de objeto para o cinema.

$\mathrm{Na}$ etapa experimental da pesquisa, os conceitos destacados na revisão de literatura são

\footnotetext{
1 "Ridley wanted this machine to be fairly delicate, briefcase size, easily portable, but it also had to look very dangerous sitting on a desk, very threatening, and sort of like a giant tarantula. Since it isn't dangerous because it's large, it had to be dangerous because it's threatening. So we decided it should breathe. My rationale for this was that the machine would draw in air samples in the immediate area. When you are scared or apprehensive, our body gives off an odor [...]. You unfold the machine and it starts itself as soon as the subject walks in the room; its arm moves around and focuses at the subject's eye. It's sort of alive in a way all by itself, and it's very, very threatening." (XIRDAL, 2006)
} 
correlacionados aos resultados obtidos na etapa exploratória. Essa análise combina a pesquisa teórica e a pesquisa empírica para analisar e avaliar a eficácia, as vantagens e desvantagens da aplicação de metodologia de design para a produção de objetos cinematográficos, e o seu impacto na indústria cinematográfica. Por fim, na etapa conclusiva, é apresentada a compreensão geral dos resultados analisados e a síntese desse estudo.

\section{Desenvolvimento}

\subsection{Cinema, design e objetos}

Cinema e design têm uma origem comum dos seus princípios de construção da linguagem. Suas formas de representação, assim como a da pintura, trabalham a transposição do espaço real, o do cotidiano, à um espaço plástico, o da superfície da imagem (MACHADO, 2009). Duas áreas específicas da realização de um filme têm suas nomenclaturas que, curiosamente, destacam os conceitos de design e arte na produção cinematográfica: design de produção e direção de arte. Entende-se que a relação entre design e cinema não se concebe de campos do conhecimento distintos, mas de um exercício de interdependência consumado em uma série de ações projetuais, manifestando o exercício do designer desde a criação até a finalização de um filme que visa construir uma obra estética que deve comunicar (SUETU, 2010).

O design no contexto cinematográfico, como aponta Suetu (2010), apresenta diferenças entre o design do próprio filme e o design para o filme. 0 primeiro se refere à concepção da obra como um todo. O design do filme acontece em uma escala macro, e diz respeito ao conceito ou linha estética adotada para a obra. Nesse sentido, o designer pode atuar em todo o projeto de um filme, e não apenas nos elementos específicos (SUETU, 2010).

Já o conceito de design para o filme se refere à composição dos elementos que uma cena contém (cenografia, figurino, maquiagem). O design para um filme acontece em uma escala micro, considerando que a maioria dos filmes possuem cenários e personagens que podem ser concebidos em conjunto com diversas áreas do design como, por exemplo, moda e interiores. Suetu (2010, p.22) sugere que a produção de objetos "é outra área da produção cinematográfica que conta com a formação do designer para propor cenários [e objetos] mais significativos para a construção da narrativa". Esse microcosmo atua como um elemento da direção de arte e, dentre os elementos que são de responsabilidade desse departamento, estão os objetos cinematográficos.

De modo geral, o termo "objeto" é utilizado para descrever uma infinidade de artefatos tridimensionais do dia-a-dia em todo e qualquer contexto: casa, espaços públicos, ambientes de trabalho, escolas, espaços de lazer e meios de transporte. O termo abrange desde coisas simples com uma única finalidade, até mecanismos complexos (HESKETT, 1937). Um ambiente é caracterizado por determinado conjunto de objetos. Por exemplo, ao se pensar em cama, guardaroupa, abajur, cabeceira e poltrona é provável que se esteja referindo a um espaço específico: o quarto. A forma de cada objeto dentro desse ambiente, captada pela visão, como tamanho, marca, modelo, tecnologia, condição de uso, cor, disposição no espaço, vai contribuir para identificar o usuário desse espaço (COELHO, 2006).

Objetos do contexto cinematográfico possuem peculiaridades e especificidades que interferem no momento de sua criação. Seu aspecto mais importante é sua imagem captada a partir da tela, uma vez que "ele nos chega pela forma visual e não nos serve para a função a que estamos acostumados no mundo real. (...) Trata-se da representação de um [objeto] e isto faz com que ele 
pertença a uma categoria que o designer costuma chamar de 'objeto bidimensional' " (COELHO, 2006, p.3).

O objeto cênico pode ser um objeto comum, do dia-a-dia, mas também pode ser sintético, criado integralmente a partir de softwares computacionais, ou um objeto falso, feito de materiais alternativos que simulem visualmente a forma tridimensional do objeto pretendido. Segundo Coelho (2006), não interessa se a imagem captada é de um objeto real ou não. Isso evidencia a função primordial do objeto cênico: significar - no intuito de comunicar, simbolizar ou representar uma ideia. $O$ significado desse objeto passa a ser uma qualidade que tem relações estreitas com a questão de sua identidade, ou seja, independente da veracidade do objeto cênico em relação ao mundo real, sua importância está na imagem que ele deseja representar.

\subsection{Objetos cinematográficos e sua relação com a narrativa}

O encontro entre o cinema e a narrativa ocorreu, segundo Vernet (1995), a partir de três fatores; (i) a imagem figurativa em movimento, (ii) a imagem em movimento e (iii) a busca pela legitimidade. O primeiro diz respeito à premissa de que no cinema uma imagem de uma casa não é apenas a imagem de uma casa, mas sim um discurso, um enunciado, eis aqui uma casa. A imagem em movimento se relaciona à noção de tempo e remete a transformação. Por fim, a incorporação da narrativa ao cinema é um esforço de legitimação dessa atividade, buscando equipara-la às "artes nobres" do século XIX, o teatro e a literatura. No Dicionário Teórico e Crítico de Cinema, Aumont e Michael (2006, p.209) apresentam alguns sentidos possíveis para a palavra "narrativa" propostos por Gérard Genette, restringindo ao campo cinematográfico a definição de "o enunciado narrativo que assegura a relação de um acontecimento ou de uma série de acontecimentos".

A narrativa fornece a estrutura para a concepção dos significados e das diretrizes no design em um filme. Para Tashiro (1998), os objetos têm papel importante nesse contexto pois, quando utilizados na narrativa, vão produzir significados específicos para o filme. Com uma presença eloquente na cena cinematográfica, o objeto torna-se expressivo dentro do espaço dramático através de seus significados, podendo até assumir um papel coadjuvante e tomar a condução da narrativa. Como afirma Coelho (2003, p.486),

A necessidade de utilização do objeto como instrumento da narrativa ou como marcador de cenas e passagens não é própria do texto cinematográfico, mas de qualquer processo narrativo. $O$ objeto é usado normalmente como âncora da memória.

Ao conceber o conceito visual do filme o designer de produção vai explorar a relação entre a imagem do filme e a imagem da realidade na qual ele se referencia, beneficiando-se, a partir de associações, dos significados preexistentes dos objetos. Como aponta Tashiro (1998, cap. I), "objetos e espaços se inserem em uma narrativa com associações de valor preexistentes; eles mudam a história através de seu uso" ${ }^{2}$ (tradução da autora). Entretanto, uma associação implícita não é totalmente garantida já que os espectadores podem, ou não, apreender os significados pressupostos do filme. Como vários objetos possuem uma gama similar de sentidos, eles vão produzir uma pluralidade interpretativa que pode, ou não, ser correspondente à sua função narrativa.

Tashiro (1998) levanta um outro ponto importante da relação entre narrativa e objeto, que

\footnotetext{
2 "Objects and spaces enter a narrative with preexisting associations of value; they leave the story changed by their use." (TASHIRO, 1998, cap.I)
} 
é a situação de desconexão que ocorre quando o objeto não condiz com a narrativa, prejudicando a leitura do filme. Se a presença de um objeto não for motivada pela narrativa, e se o design se sobressai sem um propósito temático evidente, ele passa a funcionar em uma autonomia relativa que desconsidera e pode prejudicar a narrativa. Além disso, se o objeto desperta muitas leituras implícitas, a leitura dominante (seu propósito narrativo principal) pode se tornar muito difícil (TASHIRO, 1998).

Em uma obra cinematográfica é possível reconhecer inúmeros objetos do cotidiano como móveis, utensílios, equipamentos e veículos, que contribuem para um efeito de preenchimento arquitetônico. Esses objetos são essenciais para a construção imagética da narrativa, mesmo quando não possuem grande destaque. Além desses objetos, que aqui são classificados como "objetos apropriados pela narrativa", há também os "objetos criados para a narrativa", que são aqueles desenvolvidos estritamente para servir a uma narrativa específica. Frequentemente inseridos em contextos como os filmes de gêneros de fantasia e ficção científica, os objetos criados para a narrativa se destacam por sua singularidade e criatividade.

Objetos como esses podem não chegar às mãos do público, mas eles precisam ser construídos a partir de parâmetros suficientemente reais para dar credibilidade ao produto e, consequentemente, à ação que conduz a narrativa. Tashiro (1998, cap.I) exemplifica que "[...] um projeto arquitetônico que iria desmoronar no mundo real deve apenas 'parecer adequado' para servir ao seu propósito em um filme" ${ }^{3}$ (tradução da autora). Projetados para atender a demandas bem específicas, sejam visuais ou funcionais, esses objetos exigem do projetista um trabalho pautado por inventividade, repertório de referências, conhecimento de aspectos simbólicos e equilíbrio entre o imaginário e o concebível.

Quando é necessária a criação de um objeto exclusivamente para um filme, a definição das características desse objeto é de responsabilidade do departamento de arte, mas a concepção do objeto em si pode ficar a cargo de profissionais de diversas áreas como design, arte ou engenharia. Considerando a natureza do objeto cinematográfico, entende-se que as atividades necessárias para sua concepção se aproximam muito da capacidade do designer de produto. Cabe investigar, portanto, as metodologias de design para a elaboração de um objeto real, e como essas metodologias podem funcionar para projetar um objeto cinematográfico.

\subsection{Metodologia de design e seu potencial para a aplicação no desenvolvimento de objetos cinematográficos}

A elaboração de um objeto, artefato, ou produto que apresente diversas características, decorre de um processo de edificação, quer dizer, a construção de um produto se dá a partir de passos (racionais e intuitivos) realizados pelo designer ou equipe de projeto até atingir o resultado final, uma solução projetual (PAZMINO, COUTO, 2010). Segundo Munari (1998), um método de projeto consiste em uma sequência operações necessárias, dispostas em ordem lógica. Diversos autores tratam de estudos referentes à construção de metodologias de design (ver, por exemplo, BÜRDEK, 2010; MUNARI, 1998; LÖBACH, 2001; BAXTER, 2000). De modo geral, as atividades propostas nessas metodologias projetuais são organizadas em quatro grandes etapas ou fases: preparação, geração, avaliação e realização.

\footnotetext{
3 "An architectural design that would fall apart in the real world must only "look right" in a film to fulfill its purpose, for example." (TASHIRO, 1998, cap. I)
} 
Para o desenvolvimento desta pesquisa, foram estudadas as metodologias projetuais propostas por Löbach (2001) e Baxter (2007), ambas com foco em produtos industriais. Na análise dessas obras, além da visão geral das fases de projeto, são destacadas as principais atividades e ferramentas propostas pelos autores. Na etapa exploratória deste estudo, as atividades e ferramentas aqui destacadas foram postas em prática, e algumas vezes adaptadas, para o desenvolvimento do objeto cinematográfico.

Em suas obras, Löbach (2001) e Baxter (2000) demonstram que o processo de design é um processo criativo, bem como de um processo de soluções de problemas, que deve ser executado de modo sistemático e interdisciplinar, incorporando ciências sociais, tecnologia e arte em uma única atividade. É consonante, em ambas as metodologias, o enfoque na pesquisa e no levantamento de dados que devem anteceder o início da criação. Baxter (2000) sublinha que a atividade de desenvolvimento de um produto requer pesquisa e planejamento cuidadoso. Löbach (2001) nomeia essa primeira fase de preparação, configurando-a como um momento de realização da análise do problema. Algumas atividades dessa fase, propostas pelos autores, são: (i) a descoberta e o entendimento de um problema (que, em uma situação de produção industrial, pode acontecer por meio de contato com a direção de uma empresa, ou com especialistas em pesquisa de mercado); (ii) a coleta de informações (com utilização de ferramentas diversas, como, por exemplo, conversas, entrevistas, formulários, observação, leitura de pesquisa, leitura de normas); (iii) a análise comparativa do produto (algumas ferramentas propostas são: pesquisa de produtos concorrentes e similares, análise funcional, análise estrutural, benchmarking); (iii) definição do problema e dos objetivos do projeto (que pode ser registrada como um documento, definindo as diretrizes e metas do projeto).

Já a segunda fase, de geração, deve ser pautada principalmente pela criatividade na produção múltipla de ideias baseadas nas análises previamente realizadas, criando uma diversidade de alternativas para solucionar o problema em questão (LÖBACH, 2001; BAXTER, 2000). Algumas das principais atividades dessa fase são: (i) projeto conceitual e concepção do estilo (painel de estilo de vida, painel de expressão do produto e painel de tema visual são exemplos de ferramentas propostas); (ii) execução de esboços e modelos tridimensionais.

A fase de avaliação consiste no exame das soluções geradas e na seleção da uma opção. A principal atividade é a avalição, com base nos critérios previamente definidos, das alternativas geradas e a decisão da melhor opção (LÖBACH, 2001; BAXTER, 2007). Löbach (2001) aponta que, nas empresas industriais, essa avaliação e seleção normalmente é feita com a participação dos responsáveis pelo planejamento de produtos, design de produtos e comercialização.

Por fim, na fase de realização, acontece a materialização da alternativa escolhida. As atividades principais são: (i) a execução de um protótipo do produto final; (ii) a elaboração da documentação do projeto, que pode incluir desenhos técnicos, textos explicativos e especificações para fabricação (LÖBACH, 2001; BAXTER, 2007).

O objeto cinematográfico, mesmo com as suas particularidades, tem potencial para ser concebido a partir dos métodos de design de produto aqui apresentados. Algumas características que aproximam o objeto cinematográfico de um objeto real são: a sua materialidade (o objeto precisa ser produzido de alguma forma, portanto a escolha de materiais e processos produtivos é 
importante) ${ }^{4}$; a interação com pessoas (os atores muitas vezes utilizam e manuseiam esses objetos); o comprometimento com a realidade (mesmo em filmes de ficção a verossimilhança dos objetos é importante para evitar que o espectador fique deslocado com situações demasiadamente absurdas). Identificadas as similaridades entre os projetos de objetos reais e para o cinema, e constatada a possibilidade de desenvolvimento de um objeto cinematográfico a partir da aplicação de metodologia de design, propõe-se a descrição da aplicação de metodologia de design para a concepção de objeto para um filme, e a posterior análise dos resultados desse projeto.

\subsection{Aplicação de metodologia de design para produção do objeto cinematográfico}

Nessa etapa exploratória da pesquisa é descrita a aplicação de uma metodologia de design no projeto de um objeto essencial para a produção de um curta-metragem. A demanda para o desenvolvimento desse objeto foi identificada a partir de contato com o diretor do filme $O$ Duplicado, João Pedro Oct. O filme, uma produção em desenvolvimento, propõe narrar a história de um astronauta no processo de construção de uma inteligência artificial (I.A.). O curta-metragem toma lugar em uma espaçonave que, ao longo de seu trajeto, colide com lixo espacial e entra em pane. A I.A. é uma das protagonistas do filme, e sua existência e operação se dão a partir de um aparato tecnológico, um hardware. O projeto de concepção desse objeto, que tem função cênica determinante no desdobramento da narrativa, é descrito e analisado como parte dessa pesquisa.

A metodologia aplicada ao projeto do objeto foi baseada no estudo das metodologias de design, com foco em design de produto, conforme descrito na seção 3.3, com adaptações para atender às especificidades do projeto. A Figura 1 apresenta um diagrama elaborado para organizar a execução do projeto.

Figura 1 - Diagrama de metodologia elaborado para a execução do projeto

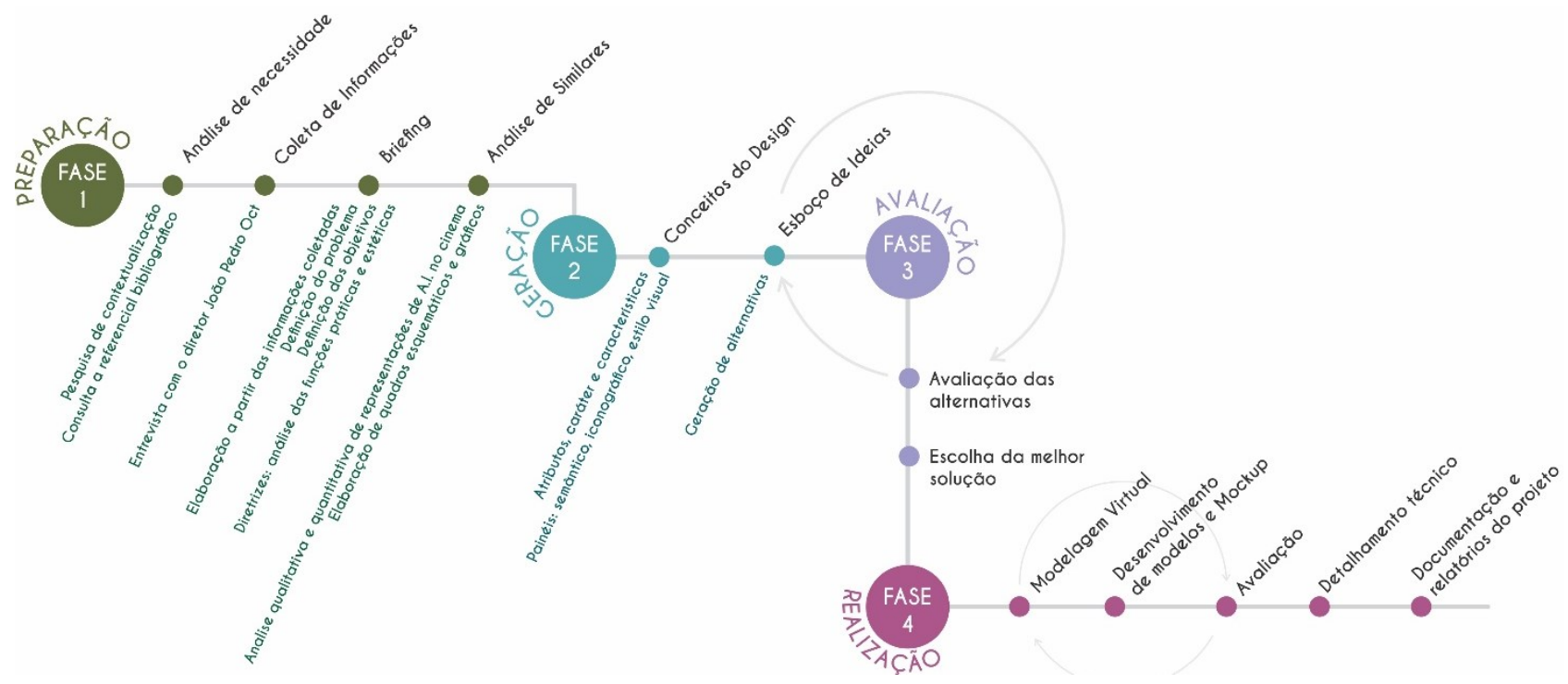

Fonte: arquivo pessoal

\footnotetext{
${ }^{4}$ No caso de objetos inteiramente virtuais, que são inseridos no filme por meio de computação gráfica e que não demandam conformação de matéria física, ainda é necessária a especificação de materiais e processos produtivos para definir a aparência do objeto em termos de formas possíveis, cores, texturas, refletividade da superfície, etc.
} 
O desenvolvimento do trabalho aconteceu em quatro fases - preparação, geração, avaliação e realização. As atividades realizadas e as ferramentas utilizadas em cada fase estão descritas no Quadro 1, e comparadas com as atividades que seriam realizadas em um projeto de produto industrial. Alguns resultados mais importantes do processo são mostrados em imagens, referenciadas no quadro.

Quadro 1 - Descrição da realização do projeto

\begin{tabular}{|c|c|c|c|}
\hline & ATIVIDADE & $\begin{array}{l}\text { APLICAÇÃO COMUM EM PROJETO } \\
\text { DE OBJETO INDUSTRIAL }\end{array}$ & APLICAÇÃO NO PROJETO DE OBJETO CÊNICO \\
\hline \multirow{4}{*}{ 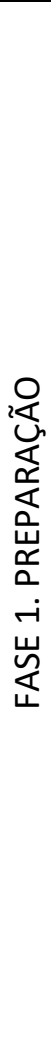 } & $\begin{array}{l}\text { Descoberta e } \\
\text { entendimento } \\
\text { do problema }\end{array}$ & $\begin{array}{l}\text { Geralmente, identifica uma } \\
\text { oportunidade de mercado, pode } \\
\text { acontecer por meio de contato } \\
\text { com uma empresa ou profissional } \\
\text { de pesquisa de mercado. }\end{array}$ & $\begin{array}{l}\text { Foi identificada a necessidade de desenvolvimento } \\
\text { de um objeto cênico para um filme, por meio de } \\
\text { conversa com o diretor do curta-metragem O } \\
\text { Duplicado. }\end{array}$ \\
\hline & $\begin{array}{l}\text { Coleta de } \\
\text { informações }\end{array}$ & $\begin{array}{l}\text { São utilizadas ferramentas diversas } \\
\text { para coletar informações dos vários } \\
\text { atores envolvidos (usuários, } \\
\text { consumidores, produtores), para } \\
\text { ter o completo entendimento do } \\
\text { problema. }\end{array}$ & $\begin{array}{l}\text { Foram realizadas diversas entrevistas com o diretor } \\
\text { do filme para coletar informações. Assim foi possível } \\
\text { entender o arco narrativo e o estilo do filme, além } \\
\text { de determinar o contexto de inserção do objeto no } \\
\text { filme, as especificidades desse objeto, seu } \\
\text { funcionamento prático e simbólico. }\end{array}$ \\
\hline & $\begin{array}{l}\text { Definição do } \\
\text { problema e dos } \\
\text { objetivos do } \\
\text { projeto }\end{array}$ & $\begin{array}{l}\text { Normalmente essas definições são } \\
\text { registradas como um documento } \\
\text { escrito, que define as diretrizes e } \\
\text { metas, e que é validado pelo } \\
\text { designer e pelo empresário. }\end{array}$ & $\begin{array}{l}\text { Foi elaborado um briefing registrando definições do } \\
\text { problema e dos objetivos, as diretrizes de materiais, } \\
\text { processos e orçamento, além da enumeração das } \\
\text { funções práticas e estéticas esperadas para o objeto. } \\
\text { O briefing foi validado pelo diretor do filme. }\end{array}$ \\
\hline & $\begin{array}{l}\text { Análise } \\
\text { comparativa do } \\
\text { produto }\end{array}$ & $\begin{array}{l}\text { Em geral são feitas pesquisas de } \\
\text { mercado para identificar produtos } \\
\text { concorrentes e traçar a estratégia } \\
\text { de posicionamento no mercado, } \\
\text { além de pesquisa de produtos } \\
\text { similares para análise de aspectos } \\
\text { diversos como função, estrutura e } \\
\text { semântica dos objetos. }\end{array}$ & $\begin{array}{l}\text { A análise foi focada em objetos similares (hardwares } \\
\text { que são suporte para o funcionamento de uma I.A.) } \\
\text { existentes em filmes diversos. Foram analisados } 25 \\
\text { objetos e coletadas informações como, por exemplo, } \\
\text { o estilo visual do filme, a capacidade de locomoção } \\
\text { da A.I., sua participação no filme. A pesquisa foi } \\
\text { condensada em painéis para melhor apresentação e } \\
\text { entendimento visual. }\end{array}$ \\
\hline \multirow[t]{2}{*}{ 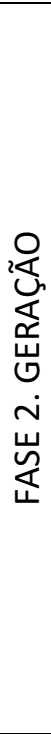 } & $\begin{array}{l}\text { Projeto } \\
\text { conceitual e } \\
\text { concepção do } \\
\text { estilo }\end{array}$ & $\begin{array}{l}\text { Geralmente é a etapa onde se } \\
\text { desenvolve e define os traços } \\
\text { básicos da forma e função do } \\
\text { produto, visando produzir um } \\
\text { conjunto de princípios funcionais e } \\
\text { de estilo. Painéis de imagens } \\
\text { visuais (painel de estilo de vida, } \\
\text { painel de expressão do produto e } \\
\text { painel de tema visual) são } \\
\text { exemplos de ferramentas } \\
\text { propostas. }\end{array}$ & $\begin{array}{l}\text { Foram utilizadas três ferramentas principais de } \\
\text { ajuste sensorial: (i) painel de estilo visual do filme } \\
\text { (para garantir que o objeto esteja em conformidade } \\
\text { com a concepção visual do filme (Figura 2)); (ii) } \\
\text { painel semântico da I.A. (para criar referências } \\
\text { visuais que representem a inteligência artificial); (iii) } \\
\text { painel de objetos relacionados (para entendimento } \\
\text { dos objetos que estarão em cena junto com o novo } \\
\text { objeto que está sendo projetado). Estes painéis } \\
\text { foram fundamentais para estabelecer uma } \\
\text { comunicação clara e direta da linguagem visual } \\
\text { pretendida para o objeto com o diretor do filme. }\end{array}$ \\
\hline & $\begin{array}{l}\text { Execução de } \\
\text { esboços e } \\
\text { modelos } \\
\text { tridimensionais }\end{array}$ & $\begin{array}{l}\text { Produção de diversas alternativas } \\
\text { para solucionar o problema em } \\
\text { questão, usando como técnica a } \\
\text { associação livre de ideias. Nessa } \\
\text { fase se prepara e executa esboços }\end{array}$ & $\begin{array}{l}\text { Estágio 1: geração de alternativas 2D (desenhos). } \\
\text { Estágio 2: modelos virtuais 3D de algumas opções, } \\
\text { possibilitando um melhor entendimento da forma e } \\
\text { teste de opções de composição, acabamento e } \\
\text { dimensões. Alguns resultados dos estágios } 1 \text { e } 2 \text { são }\end{array}$ \\
\hline
\end{tabular}




\begin{tabular}{|c|c|c|c|}
\hline & & $\begin{array}{l}\text { de ideias ou modelos } \\
\text { tridimensionais dos detalhes e } \\
\text { alternativas mais promissoras }\end{array}$ & $\begin{array}{l}\text { apresentados na Figura } 3 . \\
\text { Estágio 3: modelos físicos (mock-ups), utilizando } \\
\text { materiais alternativos, que foram cruciais para } \\
\text { ajustar a escala e as proporções do objeto. } \\
\text { Em todos os estágios, os desenhos e modelos eram } \\
\text { constantemente apresentadas ao diretor para } \\
\text { feedback. Nesta fase também foi muito importante a } \\
\text { realização de teste com materiais que poderiam ser } \\
\text { utilizados no objeto final. }\end{array}$ \\
\hline 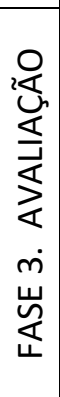 & $\begin{array}{l}\text { Avalição das } \\
\text { alternativas e } \\
\text { seleção final }\end{array}$ & $\begin{array}{l}\text { Avalição das alternativas geradas e } \\
\text { a decisão da melhor opção. Em } \\
\text { geral, essa atividade é feita com a } \\
\text { participação dos responsáveis pelo } \\
\text { planejamento de produtos, design } \\
\text { de produtos e comercialização. }\end{array}$ & $\begin{array}{l}\text { A seleção das alternativas foi realizada sempre em } \\
\text { conjunto com o diretor do filme, e aconteceu de } \\
\text { forma gradual. Ao fim de cada estágio da geração de } \\
\text { alternativas (desenhos, modelagem virtual, mock- } \\
\text { ups) era feita uma reunião com o diretor para avaliar } \\
\text { as opções e definir os modelos que seriam refinados, } \\
\text { até chegar em um único modelo acabado. Os } \\
\text { critérios para essas avaliações e decisões foram as } \\
\text { diretrizes definidas no briefing. }\end{array}$ \\
\hline \multirow{2}{*}{ 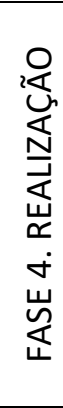 } & $\begin{array}{l}\text { Execução de um } \\
\text { protótipo do } \\
\text { produto final }\end{array}$ & $\begin{array}{l}\text { Desenvolvido para realização de } \\
\text { teste de mercado, fabricação e } \\
\text { montagem. }\end{array}$ & $\begin{array}{l}\text { Em conclusão às etapas seguiu-se para a construção } \\
\text { do protótipo com a finalidade de ser a peça utilizada } \\
\text { na produção cinematográfica. }\end{array}$ \\
\hline & $\begin{array}{l}\text { Elaboração da } \\
\text { documentação } \\
\text { do projeto }\end{array}$ & $\begin{array}{l}\text { Normalmente com elaboração de } \\
\text { desenhos técnicos, textos } \\
\text { explicativos e especificações para } \\
\text { fabricação }\end{array}$ & $\begin{array}{l}\text { Elaboração do relatório de produção especificando } \\
\text { as funcionalidades e os aspectos simbólicos } \\
\text { atribuídos ao objeto e realização do detalhamento } \\
\text { técnico. Além disso, foram feitas imagens } \\
\text { renderizadas do produto para representa-lo em } \\
\text { contexto de uso (Figura 4). }\end{array}$ \\
\hline
\end{tabular}

Fonte: elaborado pela autora

Figura 2 - Painel de estilo visual do filme

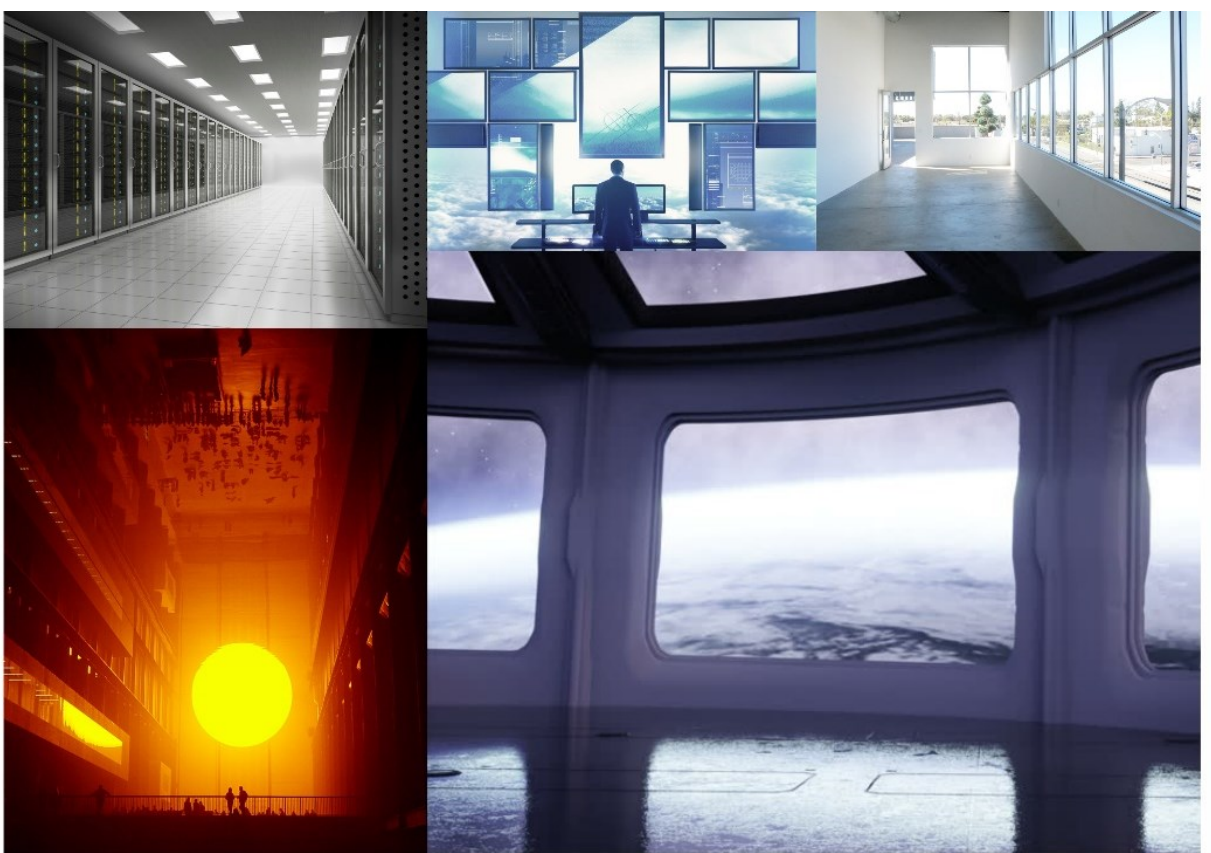

Fonte: arquivo pessoal 
Figura 3 - Geração de alternativas bidimensionais (desenhos) e modelagens virtuais tridimensionais
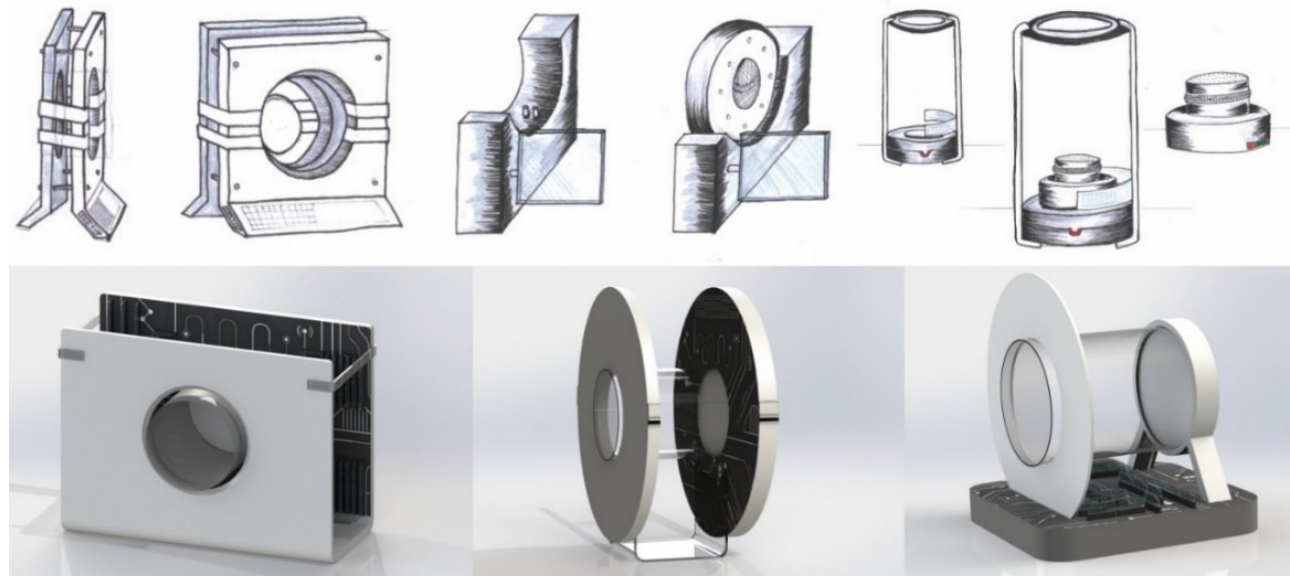

Fonte: arquivo pessoal

Figura 4 - Modelo virtual com representação de uma pessoa para referência dimensional

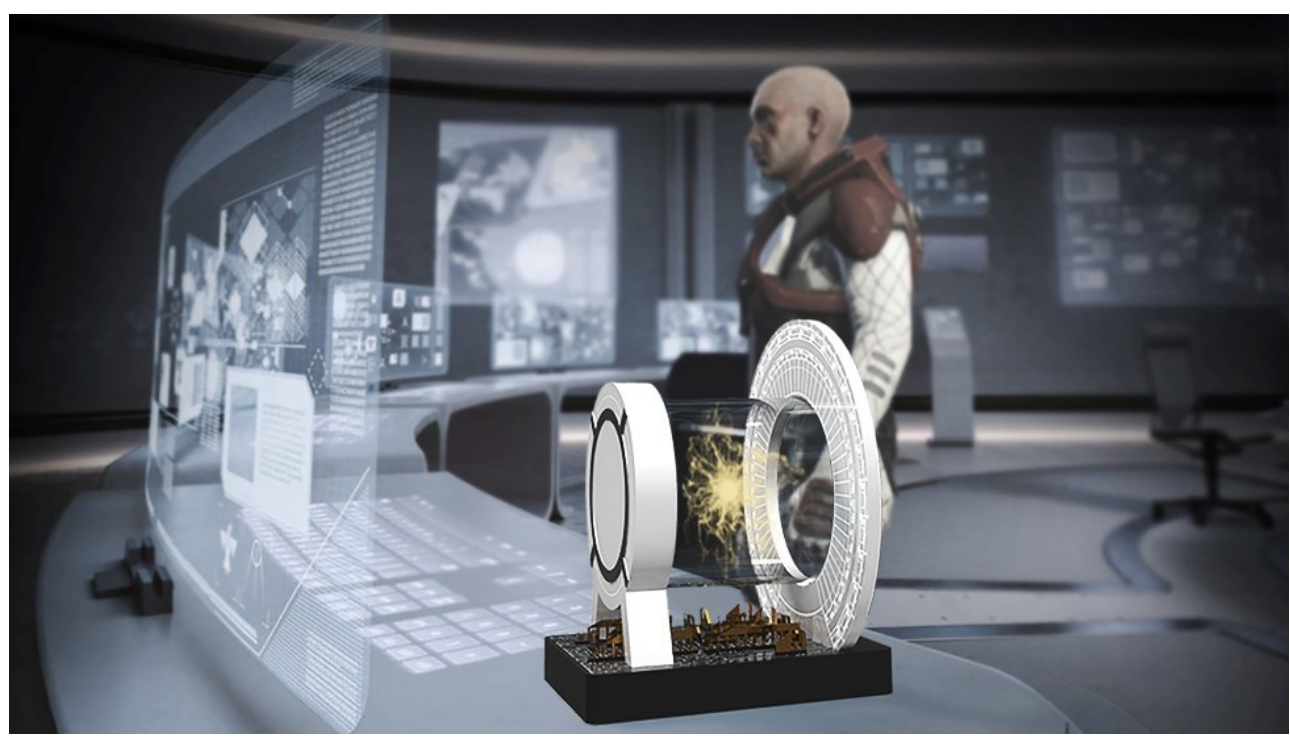

Fonte: arquivo pessoal

Ao final do desenvolvimento desse objeto foi realizada uma avaliação, juntamente com o diretor do filme, para verificar se o resultado foi adequado e se atendeu a todos os objetivos e requisitos definidos inicialmente. Além disso, a equipe de design do projeto fez uma revisão do próprio processo para identificar os pontos críticos, positivos e negativos, da aplicação da metodologia.

\subsection{Discussão de resultados}

O objeto cinematográfico desenvolvido a partir dos parâmetros da metodologia de design de produto, apresentado nessa pesquisa, alcançou um resultado satisfatório em relação às diretrizes apresentadas no briefing do projeto, atendendo às necessidades da produção cinematográfica e sendo aprovado pelo diretor. O objetivo geral do projeto - desenvolvimento e materialização de um objeto cênico que cumpra o papel de um dispositivo de operação de uma I.A.

- foi cumprido. As diretrizes de uso de materiais, processos produtivos e orçamento foram 
respeitadas. O objeto final (Figura 5) apresenta as características práticas que foram definidas inicialmente: é portátil, podendo ser carregado pelos atores, e simula uma interface, possibilitando a interação encenada do ator.

Figura 5 - Fotografia do protótipo

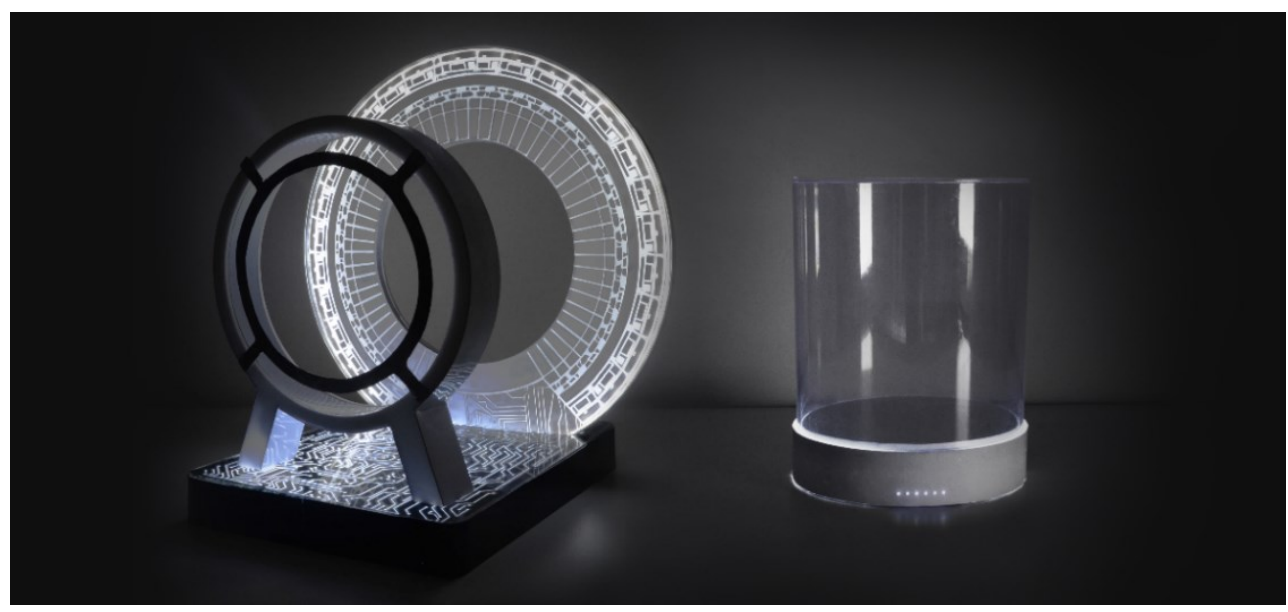

Fonte: arquivo pessoal

O visual do objeto atende aos requisitos estéticos do projeto, apresentando formas geométricas, sem estilização ou adereços, e o predomínio das cores branca e preta, que são coerentes com o estilo visual do filme. A conformação geral do objeto, que é composto por três peças encaixáveis, atende às definições de comunicação e representação estabelecidas pelo diretor: o fato de ter partes estruturais expostas (por exemplo, os grafismos de circuito), passa a ideia de uma nova tecnologia em processo de construção; alguns elementos como o indicador de bateria e a cúpula transparente trazem a ideia de fragilidade e preciosidade da I.A.; a predominância de formas circulares concêntricas remetem à característica de autocentrada; as formas alusivas a um tubo de ensaio e a um acelerador de partículas criam uma analogia conceitual de tecnologias essencialmente funcionais e sem elementos decorativos em sua forma.

Considera-se, portanto, que a aplicação da metodologia de design no desenvolvimento do objeto cinematográfico foi bem-sucedida. O uso desta metodologia permitiu uma exploração e definição cuidadosa da demanda, resultando em um conhecimento claro do problema e consequente planejamento sistemático de uma solução pertinente. Algumas das atividades e ferramentas típicas da metodologia de design foram especialmente importantes durante a execução do projeto, propiciando clareza no processo de comunicação com o diretor e possibilitando uma otimização do desenvolvimento como um todo.

A construção de painéis imagéticos e a geração de alternativas por meio de desenhos e modelos tridimensionais, por exemplo, são recursos importantes de síntese e comunicação visual que facilitaram a colaboração entre o diretor do filme e a equipe de design do projeto. A consolidação do briefing, documento elaborado na etapa inicial para condensar informações e traçar diretrizes, foi importante para alinhar as expectativas de todos os envolvidos e para diminuir a possibilidade de desvios durante a execução. $O$ uso de modelagem tridimensional virtual possibilitou a simulação de múltiplas variações de forma e acabamento, com baixo tempo de execução e sem custos com material. 
Com relação à documentação final do projeto, a produção de um detalhamento técnico, habitual no projeto de um objeto comum, possibilita a reprodutibilidade desse objeto cinematográfico. Mesmo não possuindo um aspecto de produção em série, a reprodutibilidade do objeto cinematográfico é vantajosa pois possibilita, por exemplo, que o objeto seja refeito com variação de acabamentos para se adequar às especificidades da filmagem (superfície fosca ou brilhante), ou que sejam produzidos objetos suplentes para serem usados em caso de estragos durante a filmagem.

Considerando os pontos críticos da execução deste projeto-modelo, destaca-se a dificuldade de incorporar características simbólicas ao objeto a partir desse desenvolvimento baseado na metodologia de design. Como visto na revisão bibliográfica, o objeto cinematográfico chega ao espectador pela forma visual, por meio de sua imagem captada pela tela, e sua função crucial é significar - no intuito de comunicar, simbolizar ou representar uma ideia. As metodologias de design analisadas nessa pesquisa dispõem de várias ferramentas para projetar as funções práticas de um objeto (por exemplo, a análise da tarefa, a análise de funções técnicas, a análise estrutural). A função estética e simbólica é considerada, mas as ferramentas propostas (painel de estilo de vida e painel de tema visual, por exemplo) são maiormente dedicadas à definição de estilo estético atrativo para um público-alvo específico. $O$ objeto cinematográfico precisa, além de ter um estilo estético coerente com o filme, comunicar, através das formas, características subjetivas que vão auxiliar na narrativa.

$\mathrm{Na}$ etapa de conceituação do projeto-modelo foi necessário adaptar algumas das ferramentas da metodologia de design para auxiliar na transposição de características subjetivas para a composição formal do objeto. Os painéis semânticos e iconográficos, por exemplo, foram reconfigurados: foi elaborado painel de estilo visual do filme, ao invés de painel estilo de vida; painel de objetos de cena, ao invés de painel de tema visual; painel semântico de características e sensações da I.A., ao invés de painel de expressão do produto. Mesmo utilizando essas ferramentas de síntese visual, foi necessário realizar pesquisas adicionais para identificar e associar elementos que pudessem ser incorporados para transmitir as características desejadas.

A identificação do elemento 'usuário', também se mostrou um ponto crítico. Normalmente, na metodologia de design, o entendimento de um problema contempla vários âmbitos (usuários, fabricante, cliente) que são consultados nas fases de coleta de informações e validação do produto. No desenvolvimento do produto-modelo, todas as informações estavam concentradas com o diretor do filme. Considera-se que o contato com os atores ${ }^{5}$ e equipe técnica de filmagem poderia enriquecer o processo de discussão dos aspectos práticos de uso em cena do objeto. Além disso, uma definição bem delineada do perfil dos espectadores propiciaria uma verificação prévia da eficiência conceitual dos elementos formais empregados na concepção do objeto.

\section{Conclusões}

O desenvolvimento desta pesquisa contemplou, primeiramente, a revisão de literatura sobre a atuação de designers na indústria cinematográfica, a relevância do objeto cinematográfico e sua conexão com a narrativa, e as metodologias de design e seu potencial para o desenvolvimento de produtos cinematográficos. Em seguida, apresentou a descrição do desenvolvimento de um

\footnotetext{
${ }^{5}$ Vale lembrar que o processo de produção cinematografia pode, muitas vezes, não permitir essa participação do ator no processo de desenvolvimento do objeto, em razão de sua participação na produção cinematográfica se dar em um momento posterior à etapa de desenvolvimento de objetos e cenários para o filme.
} 
objeto cinematográfico com aplicação de metodologia de design. Os resultados deste projeto foram expostos e analisados, alinhados aos conceitos teóricos, para discutir a efetividade da aplicação de metodologia de design para a produção de objetos cinematográficos.

A partir da análise da revisão bibliográfica e dos resultados do projeto-modelo, concluímos que a aplicação de metodologia de design, com algumas adaptações, é adequada e eficaz para a concepção de um objeto cinematográfico. Como vantagens da aplicação de metodologia de design para a concepção de objetos para o cinema, destaca-se o fato de tal metodologia demandar a definição cuidadosa da demanda, propiciando um claro entendimento do problema e levando a um planejamento sistemático para alcançar um resultado satisfatório. Destacam-se ainda algumas ferramentas que foram especialmente importantes durante a execução do projeto, como os painéis imagéticos e a geração de alternativas por meio de desenhos e modelos tridimensionais, que propiciaram clareza no processo de comunicação com o diretor do filme. Outras atividades, como a construção do briefing e a modelagem tridimensional virtual, foram importantes para otimizar o desenvolvimento como um todo, propiciando economia de tempo e redução de custos. Foram necessárias adaptações na etapa de conceituação do projeto, para auxiliar na transposição de características e significados subjetivos para a conformação formal do objeto.

O estudo da aplicação da metodologia de design na concepção de objetos para o cinema contribui para o conhecimento científico na área de design, além de ampliar a discussão acerca dos limites do campo de atuação do designer. Com profissionais da área de design ocupando cada vez mais funções no processo de produção de um filme, integrar as áreas de cinema e design passa a ser um processo palpável e plausível. A possibilidade de mesclar as duas áreas permite uma oportunidade de exploração de um viés pouco difundido no design brasileiro, associando-o ao mercado do cinema nacional, através do design de produção, criando, assim, novos espaços de atuação para o profissional do design.

Como trabalhos futuros a partir deste, são oportunas pesquisas que considerem a aplicação da metodologia projetual no desenvolvimento de objetos cênicos para grandes produções cinematográficas, que demandem diversos objetos de complexidades e desafios elevados. Ademais, é o oportuno o estudo e desenvolvimento de uma metodologia específica para o design de objetos cinematográficos, que considere as suas particularidades, culminando na possibilidade de uma nova ramificação de ensino para campo do design.

\section{Referências}

AUMONT, Jacques; MICHEL, Marie (2001). Dicionário teórico e crítico de cinema. Trad. Eloisa Araújo Ribeiro. 2a Edição. Campinas: Editora Papirus, 2006.

ASSUNÇÃO, Amadeus De M.; ROCHA, Bruna G. da.; VILELA, Thyenne. Metodologia de design e produção cultural. P\&D Design 10 Congresso brasileiro de pesquisa e desenvolvimento em design. São Luiz, 2012. Disponível em <https://www.eed.emnuvens.com.br/design/article/view/153> Acesso em: 24/02/2018

BATISTA, Mauro. A pesquisa sobre design de produção: um breve balanço e um percurso histórico. Revista Design, Arte e Tecnologia - Revista da Universidade. Anhembi, São Paulo, vol. 4, 2008.

BAXTER, Mike R. Projeto de produto: guia prático para o design de novos produtos. 2 ed. Re. São Paulo: Blucher, 2000. 
BÜRDEK, Bernhard E. Design: História, teoria e prática do design de produtos. São Paulo: Blucher, 2010.

COELHO, Luiz Antônio L. 0 papel narrativo do objeto cênico. P\&D Design 70 Congresso brasileiro de pesquisa e desenvolvimento em design. Paraná, 2006. Disponível em: <https://pt.scribd.com/ document/350703740/COELHO-Luiz-O-papel-narrativo-do-objeto-ce-770-nico-pdf> Acesso em: $28 / 08 / 2017$

O objeto na condução narrativa: o caso 0 Ano Passado em Marienbad, em Estudos de Cinema, Ano III 2001, Mariosaria Fabris et al (org.), Porto Alegre, Sulina, 2003, pp. 485-490.

FILHO, Paulo C. C.; FILHO, Celso H. L.; DINIZ, Paulo F. D. Revisitando a loja de répteis: estudo de caso sobre as interfaces entre o cinema e o design. Revista Científica/FAP, v.12, p.243-261. Curitiba, 2015. Disponível em <http://periodicos.unespar.edu.br/index.php/revistacientifica/ article/view/1421/775> Acesso em: 23/02/2018

GUTEMBERG, Alisson; LIRA, Bertrand. A Narrativa Cinematográfica: O Imbricamento de Som e Imagem na Produção de Sentido em O Céu de Suely. ANIMUS, v.15 n.30. p.280-293, 2016. Disponível em < https://periodicos.ufsm.br/animus/article/view/21771/pdf> Acesso: 13/08/2017

HESKETT, John. 1937. Design. Trad. Márcia Leme. São Paulo: Editora Ática, 2008.

LÖBACH, B. Design industrial: bases para a configuração dos produtos industriais. s. I.: Edgar Blücher, 2001.

MACHADO, Ludimila Ayres. Design e Narrativa visual na Linguagem Cinematográfica. 2009. 164f. Dissertação (Mestrado) Faculdade de Arquitetura e Urbanismo da Universidade de São Paulo, São Paulo, 2009.

MUNARI, Bruno. Das coisas nascem coisas. São Paulo: Martins Fontes, 1998.

PAZMINO, Ana Veronica Paz y Mino; COUTO, Rita Maria de Souza. Modelo de ensino de métodos de design de produtos. 2010. Tese (Doutorado)-Pontifícia Universidade Católica do Rio de Janeiro, Departamento de Artes e Design, 2010 Disponível em: <http://www2.dbd.puc-rio.br/pergamum /biblioteca/php/mostrateses.php?open=1\&arqtese=0721262_2010_Indice.html>

SUETU, Claudio Yutaka. O design de efeitos especiais no cinema. 2010. 119f. Dissertação (Mestrado) Universidade Anhembi Morumbi, São Paulo, 2010.

TASHIRO, C. S. Pretty Pictures: production design and the history film, Texas: University of Texas Press, 1998. Kindle Edition. ISBN 978-0-292-78692-9

TURNER, Graeme. Cinema como prática social. 1a Edição. São Paulo: Editora Summus, 1997.

VERNET, M. Cinema e narração. In: Aumont, J. et al. A estética do filme. São Paulo: Papirus, 1995.

XIRDAL, Zephyrin. Anthropology voight-kampff style. 2006. Disponível em <http:// xirdalium.net/2006/04/14/anthropology-voight-kampff-style/> Acesso em: 27/09/2017 